\title{
The Application of Comprehensive Materials in Modern Jewelry Design
}

\author{
Xu Zhen ${ }^{1}$, Zhang Xiaoyan ${ }^{2}$ \\ I( Shanghai University of Engineer Science, Shanghai 261600, China ) \\ ${ }^{2}$ (Shanghai University of Engineer Science, Shanghai 261600, China)
}

\begin{abstract}
With the continuous improvement of people's living standards, jewelry has been more and more into our modern life. Jewelry is not only the use of gold, platinum, silver and other precious metal materials, but put more materials into creation in order to fully show the wearer's personality. The jewelry is also not only a symbol of wealth.It has become the carrier of ourselves to highlight our own unique character and identity. When it comes to jewelry, people tend to think it as a symbol of wealth and social status. Gold, platinum, diamonds and gemstone has occupied a very important position in jewelry all the time. At the end of the 19th century to the beginning of the 20th century, the artistry in jewelry design has significantly improved , and has made a successful attempt in the fusion of multicultural tradition, which is closely related to the social life style and the popular tendency of thought.Jewelry design started the pace of modernization.
\end{abstract}

Keywords: - comprehensive material, Jewelry design, philosophy of technology, diversity, unity

\section{THE ROLE OF MATERIALS IN JEWELRY DESIGN}

Jewelry is often referred to as a small sculpture. 'sculpture jewelry, jewelry or a sculpture, is the result of jewelry revolution in Europe of1960s and1970'. Jewelry is more delicate and meticulous than bigger sculpture. It is not just a simple and cold work, but the mode to involve and vent confusing feelings. It is a living and smart living. Whether it is traditional materials like gold, silver, gemstone or new materials including textiles, leather, plastic , materials in jewelry design in the use of soft, rigid flexible thickness, the characteristics and performance of different will affect the visual rhythm and the corresponding level of beauty. The change and innovation of materials is a kind of special carrier,which gives new charm to the modern jewelry design . In the whole development process of jewelry design, application and innovation of material plays a role in promoting, and properties, texture and color of materials directly affects the expression of jewelry design concepts.

\section{THE DIVERSIFICATION OF MODERN JEWELRY DESIGN AND THE DIVERSIFICATION OF MATERIALS SELECTION}

In the modern jewelry design, designers sometimes use material in different fields, and sometimes look for ordinary materials in daily life and change them,and sometimes even transform the concept of completely different materials. In short, the use, restructuring and recreation of materials can help designers to reflect the modern jewelry which focus on human nature, environmental protection, personalized new design concept.

Design concept of modern jewelry is showing a diversified development trend, which mainly reflected in the impact of material value on design becomes smaller, the value of design is rising.The way to wear jewelry has been greatly expanded.The use of functional aspects has innovation and expansion.Commercialization, life and popularizationhasbecomethenewtrendofmodernjewelrydesign. Material selection of modern jewelry design especially the concept of avant-garde jewelry design has become quite broad. It is not limited to precious metals such as gold and silver, a variety of new materials and traditional materials such as fiber, plastic, glass, resin, silica gel, cloth, silk, foam, paper, and wood, iron, copper, aluminum, stainless steel, titanium, etc. has a lot of using in the modern jewelry design.

\section{THE CATEGORY AND SIGNIFICANCE OF SYNTHETIC MATERIALS APPLIED IN MODERN JEWELRY DESIGN}

Comprehensive materials have been widely used in modern and contemporary visual arts, and it has been explored and studied by many artists.Its performance is the use of a variety of material characteristics of the material to remix and match, so as to achieve the unique visual experience which a kind of single material can not show. Its strength is changing our traditional taste of art in the past, and then aesthetic habits, and then attack the concept of art which we have become accustomed to. It has won the admiration and love of artists, but also to meet the needs of people in the art of aesthetic, bring people a variety of choices and artistic form. 
Although the traditional jewelry which gemstone inlaid on gold and silver is combined by a variety of materials,but we cannot put it in the same breath as modern synthetic materials. Although these gems and precious metals come from different kinds of minerals, but rare and expensive is their common attribute. Application in the modern jewelry design of comprehensive materials should be obtained from the broader category to find out a pile of pearls and rediscover human decorating their own aesthetic impulse.Material selection of modern jewelry design especially the concept of avant-garde jewelry design has become quite broad.And it has not rigidly adhere to the use of a material to complete the design and production, integrated materials with its more extensive expression of the material, a more diverse visual experience has gradually been favored by the designers.Each material has its own physical attributes and mental attributes given by people, so design works combined by a number of materials in accordance with the specific form will provide a new material beauty,and may be greater than the beauty of each material only .This is the important reason for the performance of modern jewelry design and application of composite materials.

Performance of comprehensive material and the adaptability of the modern jewelry design concept is embodied in: composite materials can show a more complex artistic concept.Comprehensive material can behave more unique visual effects, dissolving the precious metals and rare gems material expensive, which more conducive to the dissemination and development of the jewelry culture.Comprehensive material can meet the demands of modern jewelry on the use of new function .

\section{CONCLUSION}

It can not be denied that the material itself is the image of the work. The material has changed and it also has a new requirement for the modeling and process of jewelry at the same time.The change of the concept of modern jewelry makes the contemporary jewelry show a variety of style, the material is rich, and the creative idea is more outstanding. From the image of the material itself, the decorative effect of jewelry is obtained. It requires the designer to study the physiological and mental effects of the materials, looking for the combination of the materials and the organic unity of materials and shapes. Therefore, the ingenious use of the comprehensive material itself unique aesthetic, the development of new materials aesthetic characteristics, and the application of a variety of materials is also a new trend in the development of future jewelry.

\section{REFERENCES}

[1] Luoliting, Jewelry Material in Diversified Practice, Ceramics Jewelry, Art and Design, 2009,(08).

[2] Chris Lai husband Terry, Industry and design 5 top creative materials - metals, Shanghai, Shanghai People's fine arts publishing house, 2004.

[3] Zhangshiguang, Reversal Thinking of Jewelry Design, Jewelry Science and Technology, 2003, (3). 